\title{
Presentación Editorial
}

Editorial Presentation

Nos complace presentar a nuestros lectores, seguidores y amigos un nuevo número de la revista Discusiones Filosóficas. En este año en el cual se cumplen seis décadas de actividades ininterrumpidas del programa de pregrado en Filosofía y Letras de la Universidad de Caldas (nuestra institución editora) y en el cual la madurez de la unidad académica que lo alberga se hace evidente por la importante influencia que ha tenido sobre los estudios filosóficos en el país y por el hecho de que ya se apresta a ofrecer su propio programa de doctorado, entregamos a la comunidad académica nacional e internacional ocho artículos de investigadores nacionales y extranjeros sobre diversos problemas de su interés. Aprovechamos esta feliz ocasión para anunciar a todos los interesados que el programa de Filosofía y Letras de la Universidad de Caldas planea celebrar esta efemerides con un festival internacional de filosofía que, esperamos, congregue a estudiantes y estudiosos de nuestra disciplina.

Como se anunció arriba, para la presente entrega hemos incluido ocho trabajos que cubren diversas áreas de la filosofía. El fascículo se abre con el artículo "'Una máxima en su clase'. El problema de lo absoluto entre Novalis y Kant" de autoría de Fernando Silva, investigador del Centro de Filosofía de la Universidad de Lisboa (Portugal). En este artículo se presenta un análisis del problema de lo absoluto (desde las perspectivas religiosa, política, estética y filosófica) y se esclarece su importante rol como uno de los impulsores fundamentales del pensamiento del siglo XVIII, especialmente en la época de Kant y como epígono del idealismo alemán. El autor aborda esta cuestión en su dimensión filosófico-estética y procura explicar el modo en que el problema del pensar o experimentar lo absoluto, en forma de sistematización filosófica, tal como fue legado por Kant y sus coetáneos, fue una de las principales preguntas teóricas. recibida por toda una generación de jóvenes autores. Silva demuestra esta tesis mediante el ejemplo del poeta y filósofo Novalis, e investiga cuán abierta o negativamente éste leyó la proposición kantiana del $a$ 
priori y el edificio crítico basado en él, y logra hacer evidente la negación de Novalis de la posibilidad de experimentar lo absoluto, excepto en una «aproximación infinita». Además, especula sobre cuál podría haber sido la respuesta de Kant a las objeciones de Novalis y otros, y sugiere un camino que podría haber eximido parcialmente a Kant de los reproches de sus lectores más jóvenes. Por último, presenta la concepción de la poesía de Novalis y de Kant (hasta cierto punto) sorprendentemente cercana, como la clave para el problema filosófico del absoluto.

El fascículo prosigue con el artículo "El concepto de 'racionalidad' en el ámbito práctico", un trabajo del profesor Carlos Emilio García, que se inscribe en el campo de las reflexiones meta-éticas. En este trabajo, García se propone ofrecer una caracterización del concepto de 'racionalidad' en el ámbito práctico de Smith. El autor busca demostrar que los requisitos de racionalidad de Smith (en tanto se basan en los planteamientos de Williams) no logran proporcionar una explicación apropiada y funcional de lo que significa ser un agente completamente racional. Para tal fin, examina el requisito internalista de la razón en Williams y discute los principales defectos de esa versión de racionalidad. También muestra, con base en el análisis detallado de algunos ejemplos, que los planteamientos sobre la racionalidad de Smith y los de Williams son demasiado restrictivos y que, en consecuencia, no se pueden aplicar al caso de agentes ordinarios que deliberan en la esfera práctica de la vida cotidiana.

A continuación, hemos incluido el artículo "Representaciones conceptuales y semánticas en ciencias cognitivas" de la profesora argentina Mariela Destéfano. En este trabajo, la investigadora de la Universidad de Buenos Aires intenta dar razones en contra del argumento de Jackendoff en el que se pretende identificar las representaciones conceptuales y semánticas. Destéfano sostiene que este argumento es incorrecto porque no toma en cuenta la evidencia neuropsicológica y psiquiátrica en su contra. Para desarrollar estas objeciones, la autora comienza por clarificar filosóficamente en qué consisten ambos tipos de representaciones para luego argumentar en contra de la tesis de la identificación. Enseguida aparece el artículo "Strawson y Haack: dos propuestas alternativas y moderadas en la epistemología naturalizada" del profesor de la Universidad de Caldas Leonardo Cárdenas Castañeda. En este trabajo, Cárdenas ofrece una caracterización de la epistemología naturalizada que se puede entender como una teoría que no privilegia ni a la epistemología tradicional ni tampoco a la epistemología de 
corte científico. Según el autor, se trata de mostrar que resulta posible construir un puente entre la epistemología naturalizada y la tradicional sin necesidad de prescindir de las herramientas conceptuales de la epistemología clásica (como lo son la noción de justificación y el elemento a priori), y a la vez se puede examinar hasta qué punto aquella se distingue de ésta o si debe renegar también de tales herramientas conceptuales. Como lo ha hecho en otros trabajos, Cárdenas expone una epistemología naturalizada alternativa que no prescinde de los avances científicos ni de las herramientas tradicionales de la epistemología, aunque, por ahora, él personalmente no se compromete ni con la epistemología tradicional ni con la epistemología naturalizada.

Luego de estos planteamientos sugerentes sobre las claves más recientes de la epistemología, hemos acogido el artículo "La influencia del empiriocriticismo de E. Mach en la fundación de la psicología" de la filósofa colombiana y profesora de la Universidad del Bosque Flor Emilce Cely. En este ensayo, Cely presenta diversos argumentos que permiten rastrear la influencia de Mach en el nacimiento de tres enfoques psicológicos: el conductismo skinneriano, el psicoanálisis freudiano y la psicología de la Gestalt. La autora examina, en primer lugar, la particular interpretación que Skinner y Freud hicieron de algunos postulados de la filosofía de la ciencia de Mach. En la segunda parte de su artículo analiza la influencia de la obra de Mach sobre la psicología de la Gestalt y la fenomenología husserliana. Finalmente, Cely resalta la importancia que habría tenido para la naciente ciencia de la psicología haber realizado una interpretación correcta del plan de estudios de las sensaciones desde un punto de vista empírico y experiencial, en la convergencia entre la psicofisiología de Mach y el estudio de la experiencia consciente en fenomenología.

A continuación hemos incluido un artículo de Indalecio García, investigador de la Universidad de Salamanca, que lleva como título "El origen del lenguaje en la filosofía del joven Nietzsche. Los presupuestos de Sobre verdad y mentira en sentido extramoral". En este artículo, García nos explica que, pese a que la tradición ha considerado al lenguaje como una herramienta con miras al conocimiento, Nietzsche niega esta tesis y describe el asunto en términos biológicos: el lenguaje es causado por el instinto y su función primordial es la supervivencia del animal humano, quien, además, determina su forma de vida de acuerdo con lo lingüístico (al modo como el instinto determina la vida de las abejas o las hormigas). García procura establecer los presupuestos 
de la postura acerca del origen del lenguaje que Nietzsche expone en Sobre verdad y mentira en sentido extramoral (1873), escrito en el cual el filósofo alemán afirma que es imposible que el lenguaje tenga alcance epistemológico alguno debido a su carácter metafórico. Acto seguido hemos incluido el artículo "Los orígenes de la estética de lo cotidiano. John Dewey y la noción de experiencia estética" de la investigadora postdoctoral de la Universidad de Málaga Gloria Luque. En este trabajo, Luque explica que la estética de lo cotidiano es una nueva área de investigación que trata de trascender el limitado enfoque que había caracterizado a la estética moderna, reconociendo la continuidad entre las bellas artes y otros aspectos de la vida y reclamando el carácter estético de nuestra vida diaria. De acuerdo con Luque, los orígenes de este movimiento, que surge como una crítica a las instituciones y a las teorías ilustradas, pueden rastrearse en el pragmatismo de John Dewey y su noción de experiencia estética. La autora muestra que Dewey prepara el camino para la estética de lo cotidiano al situar el carácter estético en la experiencia, en lugar de en objetos o en situaciones específicas y por eso ella analiza la noción deweyana de experiencia estética ofreciendo una nueva aproximación desde la cual actualizar su estética. Para tal efecto, Luque examina las principales cualidades que definen el término, evidenciando su potencial para superar las críticas de Yuriko Saito.

Nuestra presente entrega concluye con el trabajo “ ¿Realidad de la ficción evaluadora o ficción de la realidad evaluadora? Apuntes literarios y cinematográficos para una crítica de la razón evaluadora" de Facundo Giuliano, investigador del CONICET en la Universidad de Buenos Aires (Argentina). En este ensayo, Giuliano parte de una pregunta que transita la frontera entre la realidad y la ficción de la evaluación e indaga el tipo de racionalidad específica que ella supone. A partir de esa idea, Giuliano toma como motivo para la reflexión algunas producciones cinematográficas y literarias que posibilitan analizar críticamente algunas dimensiones de lo que entendemos por razón evaluadora. En ese orden de ideas, el autor propone un bosquejo del antagonismo irreductible que divide el acto de educar de la obsesión por evaluar y traza ciertas coordenadas de lucha en el campo filosófico-educativo, al tiempo que señala diferentes sentidos del deseo de enseñar y el lenguaje educativo. Como si se tratara de una ida al cine o al teatro, el autor plantea diferentes momentos en el abordaje del problema: una entrada o introducción; diferentes actuaciones del problema cinematografiado; un intervalo sobre la certeza del evaluar y la extrañeza del educar y telón, como final abierto por una excusa literaria. 
Como es ya costumbre, queremos expresar nuestro más profundo reconocimiento a todas las personas que hacen posible la publicación de cada nuevo número. A los autores que nos envían sus contribuciones, a los investigadores que evalúan críticamente dichos trabajos, al estudiante de filosofía de la Universidad de Caldas Daniel Giraldo Orozco quien apoya nuestro trabajo mediante la realización de diversos procesos ténicos y al personal de la oficina de revistas científicas de la universidad de Caldas, en su incesante búsqueda de una mejor calidad editorial para cada fascículo publicado. A nuestros lectores y seguidores los invitamos, como siempre, a expresar sus opiniones sobre la revista mediante el correo institucional que ya todos conocen.

Carlos Emilio García Duque

Docente

Universidad de Caldas

\section{Como citar:}

García Duque, C.E. “Presentación Editorial”. Discusiones Filosóficas. Jul.- Dic. 20 (35), 2019: 7-11. DOI: 10.17151/difil.2019.20.35.1 